\title{
A dimensão casual-explicativa dos tipos ideais: a contribuição metodológica de Max Weber para a sociologia contemporânea
}

Gert Albert

\section{Resumo}

O artigo propóe uma leitura e atualização do conceito weberiano de tipo ideal a partir do conceito de non-statement view de Roland Giere. Conforme este último, teorias consistem em modelos teóricos e hipóteses. Da mesma maneira, os tipos ideais de Weber não consistem em proposições substantivas, mas são idealizações teóricas não falsificáveis das quais derivam, contudo, hipóteses para serem falseadas ou confirmadas. O estatuto epistemológico dos tipos ideais weberianos não consiste em proposições descritivo-causais, mas, sim, em definiçóes. Dessa forma, logramos não apenas uma nova interpretação do legado epistemológico weberiano, mas também abrimos caminho para sua interlocução com a atual filosofia da ciência.

Palavras-chave: Max Weber. Ronald Giere. Tipos ideais. Non-statement views.

\section{Teorias como non-statement views}

\section{I.I Modelos teóricos}

O conceito de non-statement view surgiu como uma alternativa para a filosofia da ciência até então hegemônica nos anos 60/70 do século XX. De acordo com a concepção vigente, as teorias estáo estruturadas na forma de um sistema axiomático dedutivo (GIERE, 1994, p. 276). Os axiomas das teorias são compreendidos como proposiçôes (statements) que, em princípio, podem ser verdadeiras ou falsas. Alguns desses axiomas são entendidos como generalizaçôes universais confirmadas empiricamente, assumindo, assim, a forma de leis. Tratam-se, portanto, de atribua a autoria da obra, forneça um link para a licença, e indicar se foram feitas alterações. 
leis científicas que se reportam a um mundo real sobre o qual fazem predições. Os representantes do non-statement view contestam esta visão e sustentam que tal reconstrução filosófica não reflete realmente a prática científica. Uma reconstrução adequada, segundo Ronald Giere (1988, p. 84), concluiria que teorias não são sistemas interpretativos ou formais de tipo axiomático, mas que elas consistem apenas em "modelos teóricos" ou "hipóteses teóricas".

Mas, o que são modelos? Modelos, segundo a psicologia cognitiva, consistem em meios pelos quais os cientistas representam, para si mesmos, os sistemas do mundo real. Giere (1988, p. 78) chega a falar de "entidades construídas socialmente". Modelos podem ser formulados na forma de predicados, é o caso das leis de Newton, por exemplo (GIERE, 1994 , p. 277,1979 , p. 69). Tais predicados, em regra, costumam estar associados a outras características, tal como segue: o sistema newtoniano constitui um sistema quando e apenas quando as três leis do movimento e a lei da gravidade são suficientes e constantes. A associação de um predicado com uma ou mais leis possui o status de uma definição, mas não está associada a nenhuma exigência de verdade: não se trata de prediçóes (statement)! Leis não estão relacionadas com o mundo e não nos dizem nada diretamente sobre ele.

Em vez de simplesmente nos referimos às leis de Newton, podemos incluir essas leis em nossa definição. Assim, consideramos que um sistema newtoniano de partículas é um sistema apenas quando as três leis do movimento e a lei do movimento são constantes, de tal forma que: 1) um corpo em repouso tende a permanecer em repouso, e um corpo em movimento tende a permanecer em movimento; 2) a força é sempre diretamente proporcional ao produto da aceleraçáo de um corpo pela sua massa; 3) para toda ação, existe sempre uma reação oposta e de igual intensidade.

Os predicados descrevem os modelos da teoria, ainda que os predicados na definição sejam detalhadamente especificados através das leis. No exemplo mencionado, as leis de Newton estão formuladas de modo verbal. Elas também podem, é claro, ser formuladas de maneira matemática. 


\subsection{Hipóteses teóricas}

Além de modelos, teorias contêm também "hipóteses teóricas" (GIERE, 1979, p. 69, 1988, p. 80, 1994, p. 277). Tais hipóteses possuem a seguinte forma: "ao sistema X corresponde o predicado P", ou seja, hipóteses teóricas relacionam certos predicados com sistemas reais existentes no mundo. Um exemplo seria o seguinte: o sistema solar é um sistema newtoniano de corpos. Enquanto os predicados podem ser tanto verdadeiros quanto falsos, as hipóteses teóricas apresentam proposiçóes (statements) contingentes que podem ser verdadeiras ou falsas.

Hipóteses teóricas podem, portanto, "relacionar predicados ou modelos a um sistema real ou mesmo a uma classe de sistemas" (GIERE, 1979, p. 71). Em geral, as teorias consistem em generalizaçóes sobre uma vasta área de sistemas reais. A hipótese mais geral proposta a partir da mecânica dos corpos de Newton provém do físico e matemático francês Laplace em 1800: "todo o universo consiste em sistema newtoniano de corpos".

Além de hipóteses teóricas, concebidas como máximas generalizaçôes possíveis, certamente teorias não consistem apenas de modelos teóricos mas também de uma numerosa família de modelos. $\mathrm{O}$ parentesco entre modelos e famílias de modelos é resultado das leis que eles compartilham entre si e que acompanham as suas formulaçóes conceituais.

\section{I.3 Idealizações}

Uma das premissas centrais da non-statement view é que modelos teóricos não se assemelham, em todos os detalhes, a sistemas reais (GIERE, 1979, p. 80, 1988, p. 76). Modelos teóricos são, portanto, sistemas ideais.

Por essa razão, compreendemos como "idealização" todo método (experimental) ou toda proposição teórica por meio do qual as entidades dadas ou um complexo de entidades, dados métricos ou funções matemáticas podem ser substituídas por outras que, em relação às entidades originais, dados ou funçóes, podem ser alterados.' No caso destas substituiçóes deliberadas, temos uma otimização em função de nosso objetivo cognitivo.

\footnotetext{
Apoio-me aqui na definição dada por Hüttemann (1997, p. 87) para os “processos de idealização" na física, ainda que, tendo em vista as finalidades desta pesquisas, eu tenha alterado alguns de seus elementos.
} 
Um dos aspectos mais interessantes das idealizaçóes, no que diz respeito a proposiçóes teóricas, implica que, em princípio, ou seja, enquanto hipóteses, elas devem ser consideradas como rigorosamente falsas ${ }^{2}$. Ao conceito de idealização, podemos atribuir, por exemplo: "abstraçóes, isolamentos, simplificaçôes, negligências, exploração de dados, descrição de dados etc". (HÜTTEMANN, 1997, p. 91-104).

A idealização é, portanto, um fator central para qualquer ciência empírica, razão pela qual a filosofia da ciência precisa levá-la em consideração, afirma Ronald Giere (1994). Quando, seguindo a tese do non-statement view, entendemos as leis do movimento de Newton apenas como proposiçóes empíricas de caráter geral (statements), isso significa que, para a mecânica, elas devem ser consideradas falsas ou irrelevantes. Leis jamais são verdadeiras, mas são válidas na medida em que nos permitem certa aproximaçáo à verdade. $\mathrm{Na}$ teoria do non-statement view, leis servem apenas como receitas para a elaboração de modelos; por isso, elas não postulam nenhuma exigência de verdade (GIERE, 1994, p. 293). As hipóteses teóricas sustentam apenas que existe algum grau de aproximação entre um determinado modelo e um determinado sistema real.

A extensão dessa aproximação necessita, contudo, ser especificada, de tal forma que a hipótese a ser testada disponha de um mínimo de conteúdo empírico (GIERE, 1988, p. 81). Portanto, ao postular que modelos não supóem a exigência da verdade, ou dito de outra forma, que leis possuem apenas o status de definiçóes, a teoria do non-statement view procura levar em conta o fato universal da idealizaçáo que é inerente à ciência.

\section{I.4 Não falseabilidade}

Como, pelo menos segundo o entendimento da teoria do non-statement view, modelos teóricos não postulam a exigência da verdade, evidentemente eles também não podem ser considerados falsos ${ }^{3}$. Consequentemente,

2 Ainda que, de acordo com uma metodologia mais estrita, tal hipótese defeituosa tivesse que ser excluída do processo de pesquisa, já que foi “falsificada” pela experiência empírica, afirma Michael Schmid ( 1994, p. 419), com referência a Popper.

3 Veja-se, a esse respeito, as o resumo que Volker Gadenne faz das críticas conta o non-stetament view (GADENNE 1984, p. 143-163), bem como das críticas contra a tríplice imunização das teorias de Wolfgang Stegmüller (1980, p. I20-126). 
modelos teóricos possuem uma natural imunidade à crítica e não podem ser falsificados. No entanto, as hipóteses teóricas que são derivadas desses modelos e que utilizamos para nos aproximar da realidade, podem mostrar-se equivocadas. Mesmo assim, esse equívoco náo afeta o modelo teórico; significa apenas que o modelo teórico não pode ser utilizado naquele caso concreto. Embora o próprio Ronald Giere tenha negligenciado o caráter não falsificável dos modelos teóricos, esse não é o caso de outros representantes da teoria do non-statement view. Para uma determinada escola deste vasto movimento teórico - em especial para os estruturalistas cujo principal representante é o filósofo Wolfgang Stegmüller -, a teoria da imunidade crítica constitui o centro de sua concepção de ciência ${ }^{4}$. Para Stegmüller, a plausibilidade dessa imunidade resulta do fato de que modelos teóricos são, em si mesmos, apenas estruturas ou esquemas formais (por vezes, de caráter matemático) cujo conteúdo aplica-se à realidade das maneiras mais diferentes possíveis. ${ }^{5}$ Quando uma nova aplicação de determinado modelo para a realidade mostra-se equivocada, a teoria não precisa ser necessariamente abandonada. Por um lado, porque a comunidade científica pode aspirar a que, no futuro, possamos chegar a aplicaçóes, de fato, bem-sucedidas do modelo teórico. No pior dos casos, a comunidade científica - para quem este modelo teórico constitui sua razão de ser e sua identidade - é obrigada a reconhecer o seu caráter não paradigmático, ou seja, é obrigada a reconhecer que ele não é aplicável em todos os casos. De qualquer modo, como afirma a teoria do non-statement view, modelos teóricos possuem uma natural imunidade à crítica, o que significa que, em última instância, eles não são falsificáveis.

\section{I.5 Conclusão da primeira parte}

Para a teoria do non-statement view, teorias consistem em modelos teóricos e hipóteses teóricas. Os modelos teóricos são formulados como predicados; e, estes, por sua vez, são definidos como leis. No entanto, os modelos teóricos, bem como suas leis correspondentes, não contêm

4 Um papel importante na imunidade natural à critica, entre os estruturalitstas, é desempenhado pelos critérios teoréticos de Sneed; mas, na prática, eles não têm maior significado para nosso argumento.

5 O que representa, evidentemente, uma enorme diferença em relação à concepção dos tipos ideais do próprio Max Weber. 
proposições substantivas (statements) sobre o mundo. É apenas em um segundo momento que os modelos, por meio de hipóteses, são realmente aplicados à realidade. São somente as hipóteses, na medida em que são aplicaçóes dos modelos à realidade, que formulam proposiçóes (statements) sobre ela. Portanto, modelos teóricos são sempre modelos idealizados e sua aplicação bem-sucedida ao real pode ocorrer somente até determinado grau: o modelo e a realidade sempre podem aproximar-se ou distanciar-se em maior ou menor extensão. Quando a aplicação de um modelo resulta em equívoco, mostra-se, então, que a hipótese teórica dele derivada é falsa. No entanto, a falsificação da hipótese empírica não significa necessariamente que o modelo, como tal, seja falso, pois sempre resta a esperança de que ele possa ser confirmado quando aplicado a outros casos, em especial naqueles casos para os quais ele foi concebido.

\section{Non-statement view na teoria de Max Weber}

\section{I Tipos ideais}

Para Weber, os tipos ideais, enquanto conceitos, são construçôes mentais ou intelectuais que - devido à sua relação com pontos de vista valorativos e conhecimentos nomológicos (obtidos por isolamento, abstração e generalização de fenômenos individuais observáveis) - produzem representações ou expressôes intelectuais unívocas e não contraditórias (WEBER, [1904] 1988, p. 190). Por "expressóes conceituais", ele se refere, provavelmente, aos conceitos que, de acordo com a lógica, denominamos como predicado, ou seja, "x é um A" (HOFFMEISTER, 1955, p. 107). Weber utiliza como exemplo o tipo ideal "economia urbana - "x é uma economia urbana”. Outro exemplo da sociologia weberiana poderia ser também "x é uma forma de dominaçáo legal". Conforme a concepção tradicional, a determinação do conteúdo ou intensidade de um conceito é feita "através do esquema genus proximum e differentia specifica” (WEBER, [1904] 1988, p. 194). De acordo com esta visão, define-se um conceito mediante sua atribuição a um gênero e através da determinação de sua diferença (species, espécie), ou seja, mediante a utilização de um conceito de referência geral (genus proximum) e sua posterior especificação (differentia specifica) (HAAS, 2004, p. 737). Um exemplo nos é dado pela famosa definição 
de Aristóteles: "o homem é um animal racional". Nesse exemplo, o ser humano é definido mediante a combinação do conceito de referência geral “animal” e sua especificação pelo atributo "racional”. Contudo, na acepção weberiana, a determinação de conceitos típico-ideais não segue esse esquema (WEBER, [1904] 1988, p. 194; HEMPEL, 1993, p. 85; SCHMID, 1994, p. 425). A determinação do conteúdo de um tipo ideal ocorre de modo genético: "Se queremos tentar uma definiçãao genética do conteúdo de um conceito, resta apenas a forma do tipo ideal, no sentido anteriormente estabelecido" (WEBER, 1991, p. 109). Voltando ao exemplo da "troca", tal como utilizado pelo próprio Weber, um conceito adquire um caráter genético quando ele é posto em relação com uma lei':

O conceito de troca, por exemplo, é um simples conceito genérico, no sentido de um complexo de características que são comuns a vários fenômenos, sempre que eu deixar de considerar a significação dos elementos conceituais e, portanto, limitar-me a analisá-lo nos termos da linguagem cotidiana. Se este conceito, contudo, é posto em relação com a "lei da utilidade marginal" e se forma o conceito da "troca econômica" à maneira de um processo econômico racional, esse conceito - como qualquer outro integralmente elaborado de forma lógica - conterá um juízo sobre as condições típicas da troca. Assume, então, um caráter genético e converte-se em típico-ideal no sentido lógico; isto é, afasta-se da realidade empírica, que apenas se pode comparar e referir a ele. Algo de semelhante se pode dizer acerca de todos supostos conceitos da Economia Política: só é possível desenvolvê-los de forma genética enquanto tipos ideais. (WEBER, 1991, p. I16).

Tipos ideais generalizantes ou conceitos genéricos formados típico-idealmente são, enquanto definiçóes, especificados mediante a remissão a uma lei (e quanto a isso entendo que não existe nada em contrário) ou até mesmo de diversas leis, o que, por sua vez, determina ainda o alcance do conteúdo implicado no conceito. ${ }^{7}$

\subsection{Hipóteses teóricas}

Devemos entender os tipos ideais weberianos como proposiçóes nomológicas ou hipóteses, ou seja, statements, ou tais hipóteses seriam

6 Neste ponto do texto Weber discorre sobre a diferença entre conceitos típico-ideais simples e genéricos, ainda que ambos devam ser definidos de modo genético como aliás mostra o conceito de troca.

7 " [...] e cada tipo ideal individual é composto de elementos conceituais que são genéricos e foram modelados como tipos ideais" (WEBER, [1904] 1988, p. 20I). 
apenas o resultado de sua aplicação a realidades concretas? Tudo indica que a definição genética dos tipos ideais ainda não implica nenhuma afirmação substantiva a respeito da realidade, pois é apenas quando de sua aplicação ao real que a possibilidade de uma hipótese se coloca. Conforme Weber (1991, p. 106): "No que se refere à investigação, o conceito de tipo ideal propõe-se a formar o juízo de atribuição: não é uma hipótese, mas pretende apontar o caminho para a formação de hipóteses". "Embora não constitua uma exposiçáo da realidade, pretende conferir a ela meios expressivos unívocos" (WEBER, 1991, p. 106). E ele prossegue: “Torna-se impossível encontrar empiricamente na realidade esse quadro, na sua pureza conceitual, pois trata-se de uma utopia. A atividade historiográfica defronta-se com a tarefa de determinar, em cada caso particular, a proximidade ou afastamento entre a realidade e o quadro ideal" (WEBER, 1991, p. 106). Tudo indica, portanto, que eles possuem o caráter de padróes (KAHLBERG, 2001, p. 125-130): “[...] tipos ideais têm uma validade muito relativa e problemática se reivindicarem qualidade e enunciado histórico do empiricamente dado". Por outro lado, possuem um elevado valor heurístico para a investigação, e um enorme valor sistemático para a exposição, se apenas forem utilizadas como meios conceituais para comparar e medir relativamente a eles a realidade. Com esta função, tornam-se mesmo indispensáveis (WEBER, 1991, p. 113).

O mesmo vale para os chamados tipos ideais generalizantes da sociologia, tal como exposto por Weber nos seus Conceitos sociológicos fundamentais:

Em qualquer dos casos, tanto racionais quanto irracionais, ele [tipo ideal] se afasta da realidade e serve ao seu conhecimento da seguinte forma: mediante a indicação do grau de aproximação de um fenômeno histórico a um ou mais destes conceitos torna-se possível classificá-lo. (WEBER, [1921] 1980, p. 10).

Embora possamos achar com muita facilidade vários trechos da obra de Weber nos quais ele se expressa claramente sobre o fato de que os tipos ideais não devem ser entendidos como hipóteses, pois é apenas de sua utilização prática que tais hipóteses surgem, também encontramos trechos que nos permitem uma interpretação diferente, contradizendo nosso ponto de vista. A favor da primeira interpretação, podemos invocar o argumento 
de que Weber fala de hipóteses ou construção de hipóteses apenas em casos da utilização concreta dos tipos ideais. No entanto, esta compreensão não exclui a hipótese de que os próprios tipos ideais também devam ser compreendidos como hipóteses teóricas. Neste caso, seríamos levados a concluir que Weber entra em contradição. Esta é a razão pela qual julgo que minha leitura seja a mais correta. Passo seguinte, utilizo a lei da utilidade marginal, exemplo empregado pelo próprio Weber, como forma de demonstrar como construçôes típico-ideais podem ser consideradas hipóteses para explicar processos causais concretos:

Por outro lado, e muito especialmente, ela é [a regra ideal do princípio da utilidade marginal como norma e standard normativo-teleológico] um princípio heurístico que nos permite investigar empiricamente a ação de Robinson Crusoé - se assumirmos ad hoc a existência real de tal indivíduo - em suas determinações causais e factuais. No último caso, ela nos serve como uma construção "típico-ideal” que utilizamos como hipótese para ser "testada" em relação aos fatos, ajudando-nos assim a determinar a causalidade factual de suas ações, bem como o seu grau de aproximação com o tipo ideal. (WEBER, [1907] 1988, p. 330).

Caso a utilização que fizemos destes trechos (tendo em vista, é claro, os fins estipulados) não for unilateral e seletiva, podemos concluir o seguinte: em certos trechos, Weber dá a entender que os tipos ideais são definidos de modo genético e, nesta medida, deles náo deriva ipso facto nenhuma hipótese. Portanto, Weber utiliza o conceito de hipótese exclusivamente no contexto da aplicação de construçóes típico-ideais para a compreensão da realidade. Essa leitura nos permite interpretar sua visão como uma teoria do non-statement view ${ }^{8}$.

\subsection{Idealizações}

Weber é um defensor de determinadas formas de idealização, em especial daquelas que nos oferecem uma descrição verdadeira do mundo, pelo menos na medida em que elas detectam processos causais possíveis (em condições de interferência externa mínima), como quando determinamos quais são nossos objetos de pesquisa, quais cadeias causais serão isoladas,

8 Não obstante, no que diz respeito às ciências naturais, Weber defendia a statement view (WEBER, [1907] 1988, p. 309; SCHLUCHTER, 2005, p. 18). 
que abstraçôes teóricas serão feitas e como os dados podem ser a elas ajustados (HÜTTEMANN, 1997, p. 105). ${ }^{9}$

Na perspectiva de Max Weber vemos que a elaboração de tipos ideais pode ser compreendida também como uma idealização no sentido de isolamento, ou seja, como uma blindagem frente a fatores externos. Esse isolamento "[...] é uma idealização porque [...] uma determinada situação, na qual diversos fatores influenciam o comportamento do objeto pesquisado, é substituída por uma situação na qual a influência de fatores externos é desconsiderada" (HÜTTEMANN, 1997, p. 94). Portanto, Weber entende a formação de conceitos típicos como isolamentos conceituais, quer dizer, como desaparecimento do casual e do não essencial e como a manutenção do essencial e do adequado, ou seja, como uma forma de separar o essencial do acessório (WEBER, [1904] 1988, p. 201; [1906] 1988, p. 286). A formação de um conceito genético ou um tipo ideal de tipo genérico ocorre mediante análise, ou seja, mediante a abstração isoladora e a generalização (WEBER, [1906] 1988, p. 243). Trata-se, portanto, de "isolar, de maneira abstrata, alguns dos fatores presentes materialmente nos eventos"; fatores que, uma vez "[...] isolados conceitualmente, e tomando-se em consideração as regras gerais da experiência, propiciam sua realização" (WEBER, [1906] 1988, p. 287-289). Weber imagina, portanto, que podemos observar e isolar intelectualmente fatores de uma cadeia causal, de tal forma que o desfecho dos eventos deva ser pensado como uma relação de adequação, isso porque são relativamente poucas as combinaçóes desses fatores causais que destacamos de outros "fatores" causais dos quais, de acordo com as regras gerais da experiência, "esperaríamos" um resultado "diferente" (WEBER, [1906] 1988, p. 289).

Weber manifesta-se favoravelmente a formas fracas de idealização, rejeitando concepçóes fortes. É o que podemos concluir a partir do conceito de possibilidade objetiva (WEBER, [1904] 1988, p. 178, 192, [1906]

9 Utilizo-me, aqui, da distinção de Hüttemans, mas modifico seu significado em referência a seguinte observação de Michael Schmid (1994, p. 432): "De acordo com esse entendimento, um tipo ideal correspondente assume um caráter "ideal", isto é, ele é concebido como "um curso de eventos sem interferências" (p. 55I), na medida em que fatores específicos são considerados, enquanto causas eficientes, como produtores hipotéticos de determinados efeitos e, por essa razão, "são intelectualmente isolados e selecionados para este fim" (HÜTTEMANN, 1997, p. 104). 
1988, p. 276). Conforme o autor, construçôes típico-ideais precisam ser objetivamente possíveis. Por isso, Weber criticou certas premissas "irrealistas", insustentáveis historicamente, da escola austríaca de economia (MORLOK, 2006, p. 131). Em seus Rascunhos para as liçóes de Economia política, a base da teoria econômica abstrata é explicada por ele da seguinte forma (WEBER, 1898, p. 34): trata-se de uma combinação entre uma economia na qual não correm trocas, como aquela que podemos encontrar historicamente nas formas domésticas primitivas, e indivíduos socializados economicamente ao modo dos contadores das lojas comerciais modernas. Ora, isolando-se a economia doméstica, cálculos econômicos contábeis de tipo moderno são irrealistas, ou seja, não são objetivamente possíveis. Dessa forma, Weber não apenas contrapóe-se teoricamente contra idealizações fortes, mas também exige que a construção de tipos ideais seja historicamente possível. Na prática, sua sociologia econômica tem como meta extirpar idealizaçóes fortes deste tipo e, neste sentido, podemos afirmar que ela "des-idealiza".

\subsection{Não falseabilidade}

Após o exposto, já deveria ter ficado claro que os tipos ideais de Weber, mesmo que permaneçam sem aplicabilidade em relação à realidade, podem ainda assim permanecer inalterados em sua validade teórica. As leis hipotéticas a respeito da natureza perdem validade definitiva caso elas fracassem em apenas um único caso, elas "colapsam como hipóteses definitivas" sendo, portanto, construçôes falsas; já as construçôes típico-ideias da economia - e da sociologia, cabe acrescentar - por sua vez, "não" (WEBER, [1903-1906] 1988, p. 131). Elas têm, em princípio, uma validade empírica problemática. Em casos extremos, elas permanecem um mero jogo de ideias, quando não meras construçóes conceituais estéreis (WEBER, [1904] 1988, p. 193). Mesmo quando o tipo ideal demonstra heuristicamente extrema fertilidade, seu objetivo lógico é cumprido somente quando manifesta sua própria irrealidade, ou seja, quando ele nos conduz para a atribuição causal válida (WEBER, [1904] 1988, p. 203). A discordância com a realidade empírica nunca pode derrubar o tipo ideal concreto. Portanto, é perfeitamente lógico que a mudança científica nas ciências culturais - visto que dificilmente se pode falar de progresso em 
Weber - ocorra por suposiçóes e refutaçóes, mas antes por mudanças nos valores sociais (WEBER, [1904] 1988, p. 213). ${ }^{10}$

\subsection{Conclusão da segunda parte}

Tipos ideais são concebidos por Weber como conceitos que devem ser estipulados geneticamente e, por essa razão, eles são definidos mediante recurso a leis causais. Tipos ideais até podem ser acompanhados por complementos conceituais ou predicados, como no exemplo "X é uma forma de dominação legal”. Tipos ideais não são hipóteses; mas, na medida em que são aplicados à realidade, eles podem ser utilizados para a elaboração de hipóteses. Mesmo assim, eles conservam seu caráter idealizador, como de resto acontece com qualquer conceito científico. No caso de Weber, os tipos ideais são utilizados para a construir cadeias causais objetivamente possíveis. Os tipos ideais e a realidade correspondem entre si apenas até certo grau e mesmo que a aplicaçáo do tipo ideal à realidade náo seja bem-sucedida, é apenas a aplicação e não o tipo ideal em si que é negado. Em si mesmo, o tipo ideal não foi falsificado: eles apenas revelou não ser frutuoso do ponto de vista heurístico.

A função primordial dos tipos ideais é serem aplicados à realidade; consequentemente, eles devem servir para a explicação. Em Weber, encontramos esses tipos ideais tanto na perspectiva macrossociológica quanto microssociológica. Os seus tipos ideais macrossociológicos mais bem trabalhados podem ser encontrados em sua sociologia política servindo, neste caso, para a explicaçáo das estruturas da dominaçáo. Além deles, temos também tipos ideais microssociológicos como sua tipologia da ação. Estes, por sua vez, servem para explicar e compreender o desenvolvimento do curso e dos efeitos da ação.

10 Schmid (1994, p. 550) também entende que a não falsiabilidade é uma característica da formação de conceitos típico-ideais e, por essa razão, eles não podem ser conciliados com uma metodologia experimental. Embora eu concorde com suas críticas, também deve ser salientado que essa visão "moderna" é amplamente difundida entre a maior parte dos teóricos do non-statement view. 


\section{Explicar e compreender mediante conceitos típico-ideais}

\section{I Explicar e compreender}

Em contraste com muitas das vertentes interpretativas contemporâneas, a "sociologia compreensiva" de Max Weber não separa a compreensão interpretativa da explicação causal. Em conformidade com seu hesitante e tardio reconhecimento da sociologia como disciplina autônoma, ele unifica estes dois objetivos cognitivos oferecendo-nos uma definição dessa ciência que se funda teoricamente na ação social, sociologia " [...] significa: uma ciência que pretende compreender interpretativamente a ação social para, deste modo, poder explicá-la causalmente em seu curso e seus efeitos" (WEBER, [1921] 1980, p. 1). Por ação (incluída a omissão e a permissão) ele compreende um comportamento dotado de um sentido subjetivo. Este sentido subjetivo do conteúdo da ação pode ser interno, como o caso da busca interior realizada na contemplação budista, ou externo, como no caso das trocas comerciais (WEBER, [1913] 1988, p. 429).

Nesse sentido, o conceito weberiano de "sentido subjetivo" parece coincidir, em grande parte, com o atual conceito de "intencionalidade", ainda que não no sentido tradicional, mas no sentido de "direcionalidade", como dirá John Searle (2001). Portanto, o sentido subjetivo da ação pode ser lido como direcionalidade da ação em direção a objetos internos ou externos. A ação social, por sua vez, significa a direcionalidade da ação em relação ao comportamento de outros (WEBER, [1921] 1980, p. 1; posição distinta é sustentada por Weiß 1992, p. 49).

Weber distingue entre dois tipos de compreensão da ação. Quando procuramos compreender a ação de um indivíduo picando lenha, por exemplo, estamos nos referindo apenas à compreensáo atual do sentido visado pelo ator (WEBER, [1921] 1980, p. 5). Enquanto nesta forma de compreensão conseguimos entender apenas de que tipo de ação se trata, no caso da compreensáo explicativa somos levados a compreender a razáo da ação, ou seja, seu motivo. O motivo da ação representa para Weber um contexto de sentido que aparece para ator social ou para o observador como seu fundamento significativo. A compreensão explicativa é, pois, a intelecçáo interpretativa do contexto de sentido de um comportamento entendida como seu motivo (WEBER, [1921] 1980, p. 4). Essa intelecção 
de significados pode ser vista também como uma hipótese causal, pois os motivos da ação são, ao mesmo tempo, sua causa. A compreensão do contexto de sentido é simultaneamente uma explicação, dado que a compreensão estabelece uma hipótese causal, postulando que as razóes motivacionais representam as causas da ação e que suas consequências também são o resultado desses mesmos motivos.

O famoso preceito weberiano "motivos como causas" ("Gründe als Ursachen”) pode ser visto tanto como o princípio portador da compreensão explicativa quanto como critério de racionalidade da ação. Ele esteve no centro das discussôes filosóficas que, nas últimas décadas, discutem o problema da causalidade, da compreensão e da explicação (ALBERT, 2009; BALOG, 2008; DAVIDSON, 1985; ESSER, 1999; GEAN, 1985; GOSEPATH, 1999; VON WRIGHT, 1974). Esse preceito também influenciou decisivamente os teóricos da compreensão na sociologia. Tome-se como exemplo a tese de Herbert Blumer (1973, p. 140) de que razóes não são causas. A discussão trata do silogismo prático de Aristóteles, tema que voltou novamente a discussão com George Henrik von Wright (1974) e que também pode ser encontrado em Weber (ALBERT, 2009; SCHLUCHTER, 2000, p. 95).

O proveito motivo como causa é aplicado por Weber ao comportamento de Frederico II em 1756 [...] tendo em vista que suas intençôes e concepçôes (corretas ou errôneas) estáo na base de uma forma de uma ação motivada racionalmente (WEBER, [1903-1906] 1988, p. 68). A “interpretação causal positiva” que Weber sugeriu dos motivos das ações de Frederico II pode ser ilustrada pelo silogismo prático da seguinte maneira (WEBER, [1903-1906] 1988, p. 68):

Intenção: $\quad$ Em 1756, Frederico II tinha como intenção evitar uma derrota militar da Alemanha frente às demais potências europeias.

Percepção: Frederico II imagina que, frente à situação de 1756, o risco que a união entre Áustria, Rússia e França representava poderia ser evitado através de uma ação militar na Saxonia.

Ação: $\quad$ Frederico atacou preventivamente a Saxônica. 
De acordo com defensores do raciocínio causal, caso queiramos realmente obter uma conclusão lógica geral, devemos adicionar a este esquema uma lei ou regra que realmente descreva qual a relação causal existente entre os motivos da ação e sua execução efetiva (GEAN, 1985; ALBERT, 2009, p. 522). O esquema de Weber adotou como motivos da ação as assim chamadas pró-atitudes, tais como intenções e desejos, mas também valores ou outras aspirações e, por outro lado, as representações cotidianas dos atores, quer dizer, suas ideias, crenças e opinióes. $\mathrm{O}$ silogismo prático pode agora ser representado de forma abstrata:

\section{Intenção: $\quad$ a Pessoa $P$ deseja $O$.}

Representação: a pessoa $P$ acredita que, em dada situação, pode ser ocasionado mediante a ação $A$.

Ação: $\quad$ a pessoa $P$ produz a ação $A$.

Esse silogismo prático é aplicável apenas à ação racional, cuja causa são razóes que o próprio agente conhece. A ação afetiva, no sentido de Weber, não tem como causa tais razóes (WEBER, [1921] 1980, p. 12; cf. também Weiß 1992, p. 50-57; BALOG, 2008, p. 75). Mesmo assim, Weber insiste em compreender o conteúdo emocional de modo conceitual. Isso porque, mesmo que a compreensáo do "ser afetado" por outra pessoa inclua mais do que uma "mera compreensão intelectual", quer dizer, inclua uma "empatia" enquanto "imitação interna de um processo", o "conhecimento objetivo" requer a "articulação conceitual" do que foi vivenciado ou revivido" - sobretudo pelo controle empírico daquilo que é, portanto, apenas reconhecido de forma provisória e hipotética (WEBER, [1903-1906] 1988, p. 111, 120; Weiß 1992, p. 61). O sociólogo interpretativo, como um observador da ação, modifica aquilo que foi sentido ou revivido em conceitos intelectualmente compreensíveis e, nesse sentido - pelo menos se seguirmos aqui o raciocínio weberiano - racionaliza externamente a ação, de tal forma que ela possa assumir a mesma forma lógica que o silogismo prático. Considere-se como exemplo de "explicação" das açóes afetivas o 
caso de César: a paixão de César por Cleópatra foi a única razão para reconhecê-la como corregente do Egito e, assim, desencadear a Guerra Alexandrina (PLUTARCH, 1991, p. 181). O motivo afetivo constitui o contexto da ação, mas somente o observador a vê como uma razão significativa para o comportamento, dado que a compreensão explicativa representa uma racionalização de uma ação que, à primeira vista, parece completamente desprovida de lógica. De fato, a ação afetiva é especificamente infundada no sentido que os afetos, ainda que sejam os motores causais, não são motivos racionais para o agir. Quando Weber sugere (veja acima) que o motivo da ação forma o contexto de sentido que - seja na perspectiva do próprio agente social, seja na perspectiva do observador social - se manifesta como fundamento significativo da ação, isso deve ser interpretado da seguinte forma: no caso da açáo racional (instrumental ou valorativa), o motivo aparece tanto para o próprio ator social como para o observador como a razão do comportamento e, por esse motivo, trata-se de algo intelectualmente claro para este último. Mas no caso de ação afetiva ou tradicional isso se aplica apenas ao observador que, para fins de entendimento conceitual, racionaliza o motivo do comportamento transformando-os em causas significativas - semelhante a Weiß (1992).

Como fica claro do dito acima, o conceito de compreensão de Weber concentra-se não apenas nas disposiçôes racionais, mas também nas disposiçôes irracionais dos agentes, como hábitos, preconceitos, "erros lógicos, falhas, temperamento, humor e afetos, ou seja, no conjunto de suas “disposiçôes psicológicas" (WEBER, [1903-1906] 1988, p. 227, 114, nota de rodapé 1). Em outras palavras, a personalidade "inteira” da pessoa deve estar acessível à compreensão e explicação causal (WEBER, [1903-1906] 1988, p. 119). No entanto, em contraste com a visão romântico-naturalista, Weber enfatiza menos os aspectos irracionais e dá mais destaque aos aspectos racionais da personalidade. Ele entende como essencial na ação, ou seja, ele considera momentos de especial interesse científico para nós, “[...] a constância de sua relação interior com valores e significados últimos "[...] que tornam o nosso agir orientado por fins e, portanto, se traduzem em ação teleológico-racional” (WEBER, [1903-1906] 1988, p. 132). Por fim, a personalidade é um "complexo de motivaçôes contínuas" de ação, cuja origem pode, por sua vez, ser entendida de maneira compreensível 
ou genético-caracterológica a partir de disposições herdadas, influências educacionais, condiçóes concretas de existência e a peculiaridade individual do meio (WEBER, [1903-1906] 1988, p. 47ss).

Se, através do conceito de personalidade, Weber aborda as motivaçóes contínuas da ação, através das "leis" abstratas da economia, entendidas como "esquemas de ação racional", ele lida com os processos típicos de tomada de decisão por parte dos agentes sociais: esses processos de tomada de decisão também podem ser compreendidos explicativamente. Weber dá dois exemplos da escolha racional dos melhores meios para atingir um objetivo: o primeiro privilegia o grau maior ou menor de chance de atingir o objetivo e o segundo considera o menor custo ("o que deve ser sacrificado”) (WEBER, [1903-1906] 1988, p. 128). Dessa maneira, os esquemas de escolha racional desenvolvidos no seio da economia são entendidos por Weber como tipos ideais (WEBER, [1903-1906] 1988, p. 130-132, 140).

No entanto, não se trata de apenas modelar açóes de uma maneira típico-ideal: os tipos ideais são instrumentos metodológicos específicos para a compreensão explicativa das três questões tratadas até aqui: ações que se desenrolam em contextos significativos; os processos internos, sejam eles racionais ou irracionais, de tomada de decisão associados à açáo; bem como sua base constante na personalidade e na caracterogênese dessa personalidade. Esses processos se encaixam, assim, no modo como Weber entendia a sociologia: pois, "sem dúvida, as relaçôes compreensíveis e em particular as sequências de motivaçáo racionalmente orientadas são, para a sociologia, totalmente adequadas para atuar como vínculos entre uma cadeia causal que começa, por exemplo, com condiçóes "externas" e que termina levando de novo a um comportamento "externo" (WEBER, [1913] 1988, p. 437; BALOG, 2008, p. 77).

A conclusão é que a compreensão explicativa oferece rendimentos analíticos superiores quando comparada com a mera explicação observadora das ciências naturais (WEBER, [1921] 1980, p. 7). Esses rendimentos analíticos consistem, por um lado, em "ganhos de previsibilidade" e, por outro lado, em um entendimento motivacional que "pode ser revivido e visualizado em um sentido qualitativamente diferente dos processos existentes na natureza" (WEBER, [1903-1906] 1988, p. 69, 115). A "evidência 
psicológica" e a possibilidade de compreendê-la intelectualmente é um dos motivos centrais que levaram Max Weber a desenvolver uma sociologia de tipo compreensivo (WEBER, [1903-1906] 1988, p. 115, 126). Seu instrumento metodológico fundamental consiste na formação e aplicação de tipos ideais.

\subsection{A definição genética dos tipos ideais de ação}

Tipos ideais, isto é, conceitos típicos ideais, são definidos geneticamente mediante o uso de uma ou mais leis. Tipos ideais de açáo racional também podem ser geneticamente definidos dessa maneira. Como visto acima, uma das características fundamentais da racionalidade das açóes, em Weber, é que o princípio de "razóes como causas" se aplica a elas. Para açóes racionais, isso significa que, se um ator elabora razóes para uma ação específica, são essas mesmas razóes que causam o comportamento correspondente. Os atores movidos pela racionalidade também avaliam entre diferentes motivaçóes. Teorias ou tipologias de ação racional nos oferecem diferentes possibilidades para que, através de formulaçóes nomológicas, possamos explicar como agentes racionalmente orientados escolhem entre diferentes razões. Segundo Weber, teorias da ação racional desse tipo podem ser encontradas nas chamadas "leis" da ciência econômica. No entanto, elas "não constituem leis (naturais)", uma vez que "não são universais" "nem necessárias" (WEBER, [1903-1906] 1988, p. 113, 130, 132). Em vez de "leis", Weber prefere falar de "regras causais".

Tomando como exemplo uma observação de Weber, podemos formular uma definição genética de uma ação racional que visa a minimizar custos (WEBER, [1903-1906] 1988, p. 129) da seguinte forma.

Definição genética: uma ação x é uma ação racional de fins que visa a minimizar custos se ela satisfizer a seguinte regra causal: se um agente pesa entre os meios $y-y_{n}$ do ponto de vista do custo para atingir o objetivo z, ele escolherá o que lhe parece ser o menor custo e agirá de acordo com o meio escolhido.

Tomando em consideração a teoria da avaliação de expectativas, essa mesma definição poderia ser apresentada ainda como segue.

Definição genética: uma ação x é uma ação racional de fins que visa a maximizar interesses se satisfizer a seguinte regra causal: se um agente pesa entre os meios de ação $y-y^{n}$ do ponto de vista do benefício para atingir o objetivo z, ele escolherá a opção que lhe parece ser o meio mais adequado para atingir este fim e agirá de acordo com ele. 
Por fim, tomado em consideração certas condiçôes de partida, essas mesmas regras podem ser expressas de modo dedutivo, tal como segue:

Regra de ação: se um ator avalia entre os meios de ação $y-y^{n}$ do ponto de vista do maior benefício para atingir o objetivo 0 , ele escolherá os meios de ação que acredita podem maximizar seu benefício e agirá de acordo com eles.

Intenção: a pessoa $P$ tem em vista o objetivo $O$.

Representação: a pessoa $\mathrm{p}$ acredita que, em dada situação, o pode ser alcançado através de $\underline{y}_{i}$

Ação: a pessoa $P$ realiza a ação $y_{i}$

Nesses exemplos, podemos ver claramente que apenas quando uma lei ou uma regra geral é utilizada que o silogismo prático se torna realmente uma conclusão lógica: sem uma regra de ação, ele é incompleto. No entanto, pode-se também especificar os diferentes cursos de ação/meios de ação alternativos, com as expectativas e avaliaçóes associadas a eles, tomando-as como premissas; isso nos permite abordar tanto o processo de tomada de decisão em que meio de ação $y_{i}$ foi escolhido quanto sua "execução" concreta. O fundamental a perceber, no entanto, é que o silogismo prático está implícito de forma prática na formulação das regras de ação, ou seja, ele acaba sendo pressuposto pelas regras que explicam a açáo.

Realizado o processo de definição genética do tipo ideal de maximização da utilidade, podemos elaborar também hipóteses aplicadas a casos concretos, por exemplo: o ataque de Frederico II contra a Saxônia (em 1756) foi uma ação racional de tipo maximizador. Pode-se, entâo, tentar explicar a ação de Frederico II por meio da regra de ação de maximizar a utilidade. Também é possível verificar, em seguida, se tal explicação é verdadeira empiricamente examinando os registros do diário de Friedrich II:

Regra de ação: se um ator avalia entre os meios de ação y-y do ponto de vista do maior benefício para atingir o objetivo 0 , ele escolherá os meios de ação que acredita podem maximizar seu benefício e agirá de acordo com eles.

Premissa I: em 1756, Frederico II pretendia evitar uma derrota militar diante das potências europeias. 
Premissa 2: Frederico II acreditava, em 1756, que diante da aproximação entre Áustria, Rússia França e Saxônia, uma derrota militar podia ser evitada mediante um ataque preventivo contra esta última. (Probabilidade: 0,5 x Utilidade: 10) ou mediante inação (Probabilidade: $0,5 \times$ Utilidade: -10$)$.

Explanandum: Frederico II atacou preventivamente a Saxônia.

Além de conceitos dos seus conceitos típico-ideais de ação, que têm um caráter microssociológico, Weber também nos apresenta tipos ideais macrossociológicos: os mais elaborados e conhecidos são os seus três tipos puros de dominação (SCHLUCHTER, 2000). Weber assumiu o pressuposto de que o tipo de justificativa para a legitimidade dos governantes explica as substanciais diferenças nas estruturas empíricas de organização política (WEBER, 1980, p. 549). Sua ideia básica sobre a regularidade das formas de dominação pode ser formulada da seguinte maneira: se uma determinada forma de dominação possui um tipo específico de legitimidade, então essa mesma forma possui também uma estrutura correspondente a essa legitimidade. Nesse contexto, podemos dar uma definição genética, ainda que bastante provisória, do tipo ideal da dominação legal nos seguintes termos:

Definição genética: uma dominação de tipo legal é uma forma de organização política que satisfaz a seguinte regra: quando uma estrutura política é baseada na crença na legalidade das ordens estabelecidas, bem como no direito de aplicá-las por parte daqueles que foram designados para esta função, podemos encontrar nesta organização os seguintes elementos estruturais: responsabilidades racionalmente delimitadas, ações contínuas realizadas por funcionários públicos com base em regras legais executadas no âmbito de competências específicas, o princípio da hierarquia oficial etc.

Da mesma forma, podemos também tentar definir geneticamente a dominação carismática nos seguintes termos:

Definição genética: uma dominação de tipo carismático é uma forma de organização política que satisfaz a seguinte regra: quando uma estrutura política repousa no caráter extraordinário de uma pessoa (seja devido à santidade, ao poder heroico ou à sua natureza exemplar) e no caráter revelado da ordem que ele representa, podemos encontrar nesta organização os seguintes elementos estruturais: uma comunidade emocional, um aparato administrativo carismático, falta de regras normalmente estabelecidas, natureza antieconômica, caráter extraordinário etc. 


\section{Conclusão}

Max Weber pode ser interpretado como um defensor e, ao mesmo tempo, como um recurso da teoria do non-statement view nas ciências sociais. Tipos ideais são modelos teoréticos que têm, primeiramente, o status de conceitos definidos. Logo, tipos ideais não são proposiçôes (statements). Eles são geneticamente definidos mediante uso de leis ou regras causais. Apenas quando os tipos ideais são aplicados à realidade é que surgem hipóteses substantivas, por exemplo: "na sua guerra contra a Saxônia, Frederico II orientou-se de modo racional-calculista"; ou ainda: "os calvinistas orientam-se, na área econômica, de modo racional-valorativo; e, por fim: "o regime de Hitler foi de natureza carismática". O que estas hipóteses demonstram é que um domínio específico da realidade funciona de acordo com determinados modelos típico-ideais.

Por meio de tipos ideais pode-se tanto compreender quanto explicar. Explicaçóes causais da ação efetuadas através de tipos ideais implicam necessariamente a compreensão, mas na medida em que estão acompanhadas de regras causais, tais explicaçóes vão muito além da dela. Aqui importa recordar o silogismo prático, a quem a compreensão serve. A explicação de uma ação racional contém sempre implicitamente um silogismo desse tipo, ainda que o inverso náo, ou seja, no silogismo prático ainda não temos uma explicaçáo totalizadora da ação, pois ele não possui uma regra causal. Portanto, a explicação teórica da ação implica compreensão, mas a compreensão não nos traz uma explicação definitiva da ação. Em outros termos: se toda explicação da ação é necessariamente compreensiva, nem por isso ela se esgota neste procedimento.

Que razóes teria Max Weber para evitar conceber tipos ideais como proposiçóes? Por que tipos ideais náo representam proposiçóes, como supõe boa parte das interpretaçóes correntes? Creio que são duas as razóes que explicam isso. Em primeiro lugar, sua concepção antirrealista quanto à natureza das leis científicas. A rejeição desse tipo de realismo é particularmente evidente quando ele critica a substancializaçáo das leis da ciência, como se elas fossem forças efetivamente existentes (WEBER, [1906] 1988, p. 230; [1907] 1988, p. 363).

Ao acusar Rudolf Stammler de tal hipóstase [substancialização], Weber pretende avançar além dela e, por isso, retoma, conforme a tradição 
kantiana, a interpretação da causalidade como uma categoria transcendental de conhecimento, pois ela não se adéqua a uma substancialização realista das leis científicas. Aliás, cerca de páginas antes da citação acima, (WEBER, [1907] 1988, p. 350), ele mostra em detalhes que "[...] a causalidade não é um tipo de conexão que pertence à natureza das coisas 'em si mesmas', mas apenas 'um elemento intelectual', um conceito fundamental e uniforme da estrutura de nosso conhecimento" (WEBER, [1907] 1988, p. 363). Outro trecho da obra em que sua visão de que a causalidade é apenas uma categoria do pensamento é particularmente clara é a seguinte: "e, neste caso, não é suficiente admitirmos e permanecermos conscientes de que todo o nosso 'conhecimento' se relaciona com uma realidade construída categorialmente, por exemplo, de que a 'causalidade' é uma categoria do 'nosso' pensamento” (WEBER, [1906] 1988, p. 290).

Podemos afirmar que leis causais não estão incluídas em sua visão ontológica, na qual, ao contrário, a realidade efetiva das leis científicas é veementemente rejeitada. Da mesma forma, ao rejeitar a ideia de que de que as leis postuladas pela ciência são forças causais reais, ele admite que elas não descrevem o mundo tal como ele é, ou seja, falando em sentido estrito, proposiçóes nomológicas não são proposiçóes (statements) sobre o mundo. De forma coerente com este princípio, Weber assume a posição de que a formulação de leis é apenas um instrumento para a construção de modelos teóricos concebidos enquanto tipos ideais. E, por meio deles, podemos explicar como funcionam determinados segmentos da realidade. Em suma, Weber evita conceber os tipos ideais de forma realista.

O segundo motivo pelo qual, da mesma maneira que em relação ao non tatement view, Weber entende que os tipos ideais devem ser entendidos como afirmaçóes hipotéticas, reside no problema de sua aplicação em relação à própria realidade. Nas ciências naturais, a aplicação de modelos teóricos e de proposiçóes nomológicas já está estritamente estabelecida, pois ela se refere a entidades que, ao modo das ciências naturais, podem ser compreendidas como entidades categoricamente determinadas: átomos, moléculas, quarks, seres vivos etc. No entanto, a sociologia não é uma ciência cultural: as disposiçôes humanas para o agir são mutáveis e não há como saber, de antemão, como os indivíduos irão agir neste ou naquele 
campo social. Isso se modifica historicamente. Antes do calvinismo, por exemplo, os cristãos atuavam na esfera econômica de forma instrumental ou tradicional. Com a introdução do conceito protestante de profissão, junto à doutrina da predestinação, a conduta econômica calvinista foi reorientada no sentido normativo. O que o exemplo mostra que é que as disposiçóes para o agir podem mudar radicalmente de acordo com as mudanças culturais, neste caso, mudanças de ideias religiosas. Em consequência, outros tipos ideais precisam ser aplicados para esclarecer o agir econômico dos calvinistas. Em suma, o problema da aplicação de tipos ideais de ação é central para as ciências culturais.

A variabilidade cultural e histórica dos seres humanos como indivíduos inseridos em contextos culturais confere ao problema da aplicação das "proposições nomológicas", concebidas típico-idealmente, uma mudança profunda, uma vez que Weber não deseja que elas sejam entendidas como assertivas factuais sobre o mundo, mas apenas como "regras causais" para a construção de tipos ideais entendidos de modo instrumental, ou seja, modelos teóricos com validade empírica problemática. Se a sua aplicação não for bem-sucedida, o tipo ideal não falha; significa apenas que naquele caso dado esse tipo náo pode ser usado. Descobrir em que medida um tipo ideal é aplicável ou não é a maior tarefa dos sociólogos. Mesmo quando eles são empiricamente refutados, não se conclui daí pela falta de validade do tipo ideal.

Não é necessário acompanhar o antirrealismo de Weber nem o modo como ele dramatiza o problema da aplicação. O fundamental é que, uma vez que tenhamos entendido que Weber defendia uma visão não afirmativa, é possível inferir que sua abordagem teórica contém uma metodologia de explicação compatível com as atuais formas da teoria científica. Podemos adotar uma visão ainda mais realista que a do próprio Weber e entender os tipos ideais como modelos teóricos que nos revelam algo sobre os poderes causais que atuam no mundo social. Portanto, a sociologia contemporânea necessita trabalhar com modelos teóricos idealizados, o que torna a sociologia de Max Weber ainda perfeitamente atual. Em outros termos, isso significa que a metodologia de Weber ainda continua viva e continua válida frente a seus diversos concorrentes. 


\section{REFERÊNCIAS}

ALBERT, Gert. Weber-Paradigma. In: KENEER, Georg; SCHROER, Markus (Hrsg.). Soziologische Theorien. Ein Handbuch. Wiesbaden: VS-Verlag, 2009. p. 517-554.

WEISS, Johannes: Max Webers Grundlegung der Soziologie. München: Saur, 1992..

BALOG, 2008.Soziologie, eine multiparadigmatische Wissenschaft: Erkenntnisnotwendigkeit oder Übergangsstadium?. Wiesbaden: VS Verl. für Sozialwiss., 2008

BLUMER, Herbert. Der methodologische Standort des symbolischen Interaktionismus. In: Arbeitsgruppe Bielefelder Soziologen (Hrsg.). Alltagswissen, Interaktion und gesellschaftliche Wirklichkeit, Bd. 1, Rowohlt: Reinbek, 1973. p. 80-146.

DAVIDSON, Donald. Handlungen, Gründe, Ursachen. In:DAVIDSON, Donald. (Hrsg.). Handlung und Ereignis. Frankfurt am Main: Suhrkamp Verlag, 1985. p. 19-42.

ESSER, Hartmut. Die Logik des Handelns und Doppelte Hermeneutik. In:ESSER, Hartmut. Soziologie. Spezielle Grundlagen, Band 1: Situationslogik und Handeln. Frankfurt; New York, 1999. p. 201-215.

GADENNE, Volker. Theorie und Erfahrung in der psychologischen Forschung. Tübingen: Mohr Siebeck, 1984.

GEAN, William D. Gründe und Ursachen. In: BACKERMANN, Ansgar (Hrsg.). Analytische Handlungstheorie. Band 2. Handlungserklärungen. Frankfurt am Main: Suhrkamp Verlag, 1985. p. 195-220.

GIERE, Ronald N. Understanding Scientific Reasoning. New York: Holt; London: Rinehart and Winston, 1979.

GIERE, Ronald N. Explaining Science. A Cognitive Approach. Chicago; London: The University of Chicago Press, 1988.

GIERE, Ronald N. The Cognitive Structure of Scientific Theories. Philosophy of Science, v. 61, p. 276-296, 1994.

GOSEPATH, Stefan. Praktische Rationalität. Eine Problemübersicht. In:GOSEPATH, Stefan (Hrsg.). Motive Gründe, Zwecke. Theorien praktischer Rationalität. Frankfurt am Main: Fischer, 1999. p. 7-53.

GREVE, Jens. Praxis - Zuschreibung - Objektivität. Argumente gegen einen reduktionistischen Individualismus und ihre Kritik. Kölner Zeitschrift für Soziologie und Sozialpsychologie, v. 64, v. 3, p. 431-454, 2012.

HAAS, Gerritt. Genus proximum. In: MITTELSTRAß, Jürgen (Hrsg.). Enzyklopädie Philosophie und Wissenschaftstheorie. Stuttgart; Weimar: Verlag J. B. Metzler, 20004. p. 737. 
HEMPEL, Carl G. Typologische Methoden in den Sozialwissenschaften. In: TOPITSCH, Ernst (Hrsg.). Logik der Sozialwissenschaften, unter Mitarbeit von Peter Payer. Frankfurt am Main: Hain, 1993. p. 85-103.

HOFFMEISTER, Johannes. Wörterbuch der philosophischen Begriffe. Hamburg: Verlag von Felix Meiner, 1995.

HÜTTEMANN, Andreas. Idealisierungen und das Ziel der Physik. Eine Untersuchung zum Realismus, Empirismus und Konstruktivismus in der Wissenschaftstheorie. Berlin; New York: Walter de Gruyter, 1997.

KAHLBERG, Stephen. Einführung in die historisch-vergleichende Soziologie Max Webers. Wiesbaden: Westdeutscher Verlag, 2001.

MORLOK, Christoph. Eine kleine Soziologie des Grenznutzens. In: ALBERT, Gert et al. (Hrsg.). Aspekte des Weber-Paradigmas. Eine Festschrift für Wolfgang Schluchter. Wiesbaden: VS Verlag, 2006.

PLUTARCH. Von großen Römern und Griechen. München: dtv, 1991.

SCHMID, Michael. Idealisierung und Idealtyp. Zur Logik der Typenbildung bei Max Weber. In: WAGNER, Gerhard; ZIPPRIAN, Heinz (Hrsg.). Max Webers Wissenschaftslehre: Interpretation und Kritik. Frankfurt am Main: Suhrkamp, 1994. p. 415-444.

SCHLUCHTER, Wolfgang. Umbildungen des Charismas: Überlegungen zur Herrschaftssoziologie. SCHLUCHTER, Wolfgang. Religion und Lebensführung. Band 2. Frankfurt am Main: Suhrkamp Verlag, 1991. p. 535-554.

SCHLUCHTER, Wolfgang. Handlungs - und Strukturtheorie nach Max Weber. In:SCHLUCHTER, Wolfgang. Individualismus, Verantwortungsethik und Vielfalt. Weilerswist: Velbrück, 2000. p. 86-103.

SCHLUCHTER, Wolfgang. Handlung, Ordnung und Kultur. Studien zu einem Forschungsprogramm im Anschluss an Max Weber. Tübingen: Mohr Siebeck, 2005.

SCHULZ-SCHAEFFER, Ingo. Die "Rückwärtskonstitution" von Handlungen als Problem des Übergangs von der Logik der Selektion zur Logik der Aggregation. In: GREVE, Jens; SCHNABEL, Annette; SCHÜTZEICHEL, Rainer (Hrsg.). Das Mikro-Makro-Modell der soziologischen Erklärung. Zur Ontologie, Methodologie und Metatheorie eines Forschungsprogramms. Wiesbaden: VS-Verlag, 2008. p. 267-284.

SEARLE, John. Geist, Sprache und Gesellschaft. Philosophie in der wirklichen Welt. Frankfurt am Main: Suhrkamp Verlag, 2001.

STEGMÜLLER, Wolfgang. Neue Wege der Wissenschaftsphilosophie. Berlin; Heidelberg; New York: Springer, 1980. 
VON WRIGHT, George Henrik. Erklären und Verstehen. Frankfurt am Main: Fischer, 1974.

WEBER, Max [1903-1906]. Roscher und Knies und die logischen Probleme der historischen Nationalökonomie In: WEBER, Max. Gesammelte Aufsätze zur Wissenschaftslehre. 1988. p. $1-145$.

WEBER, Max [1904]. Die Objektivität sozialwissenschaftlicher und sozialpolitischer Erkenntnis. In: WEBER, Max. Gesammelte Aufsätze zur Wissenschaftslehre. 1988. p. 146-214.

WEBER, Max [1906]. Kritische Studien auf dem Gebiet der kulturwissenschaftlichen Logik. In: WEBER, Max. Gesammelte Aufsätze zur Wissenschaftslehre. 1988. p. 215-290.

WEBER, Max [1907]. R. Stammlers Überwindung der materialistischen Geschichtsauffassung. In: WEBER, Max. Gesammelte Aufsätze zur Wissenschaftslehre. 1988. p. 291-359.

WEBER, Max [1913]. Über einige Kategorien der verstehenden Soziologie. In: WEBER, Max. Gesammelte Aufsätze zur Wissenschaftslehre. 1988. p. 427-474.

WEBER, Max [1921]. Soziologische Grundbegriffe. In: WEBER, Max. Wirtschaft und Gesellschaft. Grundriß der verstehenden Soziologie, Tübingen: Mohr Siebeck, 1980. p. 1-30.

WEBER, Max. Wirtschaft und Gesellschaft. Grundriß der verstehenden Soziologie, Tübingen: Mohr Siebeck, 1980.

WEBER, Max. A "objetividade" do conhecimento nas ciências sociais. 5. ed. In: COHN, Gabriel (org). Coleção grandes cientistas sociais. São Paulo: Ática, 1991. 


\section{The casual-explanatory dimension of the ideal type: Max Weber's methodological contribution to contemporary sociology}

\section{Abstract}

The article proposes a reading and updating of the ideal type of Max Weber from Roland Giere's non-statement view. According to the latter, theories consist of theoretical models and hypotheses. From this, the ideal types of Weber do not consist of substantive propositions, but of theoretical idealizations that cannot be falsified, from which, however, hypotheses are derived to be falsified or confirmed. The epistemological status of ideal Weber types does not consist of descriptive-causal propositions, but of definitions. In this way we achieve not only a new interpretation of the weberian epistemological legacy, but also open the way for its interlocution with the current philosophy of science.

Keywords: Max Weber. Ronald Giere. Ideal types. Non-statement views. 